Article

\title{
A Traction Three-Phase to Single-Phase Cascade Converter Substation in an Advanced Traction Power Supply System
}

\author{
Xiaoqiong He ${ }^{1, \dagger}$, Aiping Guo ${ }^{1, *}$, Xu Peng ${ }^{1, \dagger}$, Yingying Zhou ${ }^{2, \dagger}$, Zhanghai Shi ${ }^{1, \dagger}$ and Zeliang Shu ${ }^{1, \dagger}$ \\ 1 School of Electrical Engineering, Southwest Jiaotong University, Chengdu 610031, China; \\ E-Mails: hexq@home.swjtu.edu.cn (X.H.); xupeng@foxmail.com (X.P.); \\ shizhanghai@163.com (Z.S.); shuzeliang@swjtu.edu.cn (Z.S.) \\ 2 China Railway Shanghai Design Institute Group Co., Ltd., Shanghai 200070, China; \\ E-Mail: zhouyingying@sty.sh.cn
}

$\dagger$ These authors contributed equally to this work.

* Author to whom correspondence should be addressed; E-Mail: gap@my.swjtu.edu.cn; Tel.: +86-28-8760-0731; Fax: +86-28-8760-5114.

Academic Editor: Gabriele Grandi

Received: 6 July 2015 / Accepted: 31 August 2015 / Published: 11 September 2015

\begin{abstract}
The advanced traction power supply system (ATPSS) is a new directional development for traction power supply systems, which can totally remove the neutral sections and effectively promote power quality. However, the existing converters suffer from small substation capacity. In this paper, a new configuration based on a three-level neutral point clamped (3L-NPC) three-phase to single-phase cascade converter in a substation is proposed for ATPSS, which can be used to match the capacity of the converter for high voltage and large power applications. The control strategy of the proposed converter is analyzed in depth, and the phase disposition sinusoidal pulse width modulation (PD-SPWM) with phase shift carrier SPWM (PSC-SPWM) is employed in the inverters. Then, the inductance equalizing circuit is applied for the voltage balance on the DC-link. Besides, a LC filter circuit is designed to eliminate the double line-frequency ripple of DC voltage. Afterwards, a simulation model and an experimental prototype are developed, respectively. The simulation results show that the proposed converter in this paper can not only meet the requirements of voltage and capacity for the traction network, but also improve power quality. Finally, the experimental results verify the correctness and feasibility of the proposed control strategy.
\end{abstract}


Keywords: substation; advanced traction power supply system; three-phase to single-phase converter; three-level neutral point clamped (3L-NPC); cascade

\section{Introduction}

As a focus of public opinion in 2015, the "One Belt, One Road" project has attracted the eyes of the world, in which a fast and comfortable high-speed railway would connect the East with the West $[1,2]$. The traction power supply plays one of the most important roles in a high-speed railway. The existing two-phase traction power supply in China is shown in Figure 1a. In the traction substation, the voltage of the three-phase grid is transformed into two-phase voltage by a transformer [3]. Due to the differences of phase, amplitude and frequency of the voltage between the adjacent arms $\alpha 1$ and $\beta 1$ ( $\alpha 2$ and $\beta 2$ ), neutral sections must be set between the adjacent arms [4]. There are mainly three problems caused by neutral sections: power quality issues such as unbalance, reactive power and low-order harmonics; disturbance between locomotive and network; speed loss of the locomotive. With the rapid development of high-speed railways, how to solve the aforementioned problems is a pressing problem.

The co-phase traction power supply system developed by Chinese scholars is analyzed in depth in [5], which has been put into trial operation in Meishan, China. The structure of co-phase traction power supply is shown in Figure 1b, where the neutral sections NS1 and NS3 could be canceled. The system solves the problems of power quality for electric railway with power electronic compensation devices-Active Power Compensators (APCs). Furthermore, the number of neutral sections is halved [6].

In [7], the advanced traction power supply system (ATPSS) based on a three-phase to single-phase converter is proposed, of which the system structure is shown in Figure 1c. There is a step-down transformer on the input side and a step-up transformer on the output side in a traction substation, respectively. The system achieves a balanced three-phase grid load and controls the output of the traction network flexibly by using power electronics. Besides, the system could improve power quality and cancel the neutral sections totally, which is a new type of traction power supply system and a new exploration avenue in the related research. However, the output current is significantly uplifted in the light of step-down transformer ratio, which calls for more equipment requirements. In addition, due to the current restriction on the development of power electronic devices, the traditional two-level or tri-level or five-level structure couldn't meet the requirements of the traction power supply system capacity. Nowadays, the research mainly focuses on how to enhance the system capacity. A multi-level cascade converter has the advantages of larger capacity and simpler control technique [8-10], therefore, multi-level cascade converters can be applied to this system.

Consequently, in practical applications clamped multi-level converters mainly consist of three-level and five-level converters. Theoretically, any level of the output voltage could be obtained by cascading multiple converter modules. The output transformer in a traction substation of ATPSS can be canceled to enlarge the system capacity by means of cascading multilevel converters if the interface voltage level were higher than the output voltage level $[11,12]$. At the same time, if the number of cascade modules or the levels of multi-converter module were too large, it will cause difficulties in the design of the control system. It is important to work out a proper cascade system, especially for an engineering 
application of high reliability requirements [13]. Along with the improvement of power electrical device, the new IGBTs (Insulated Gate Bipolar Transistor) make it possible that high-voltage and large-power applications come true, such as $\mathrm{SiC}$ and other devices described in [14,15].

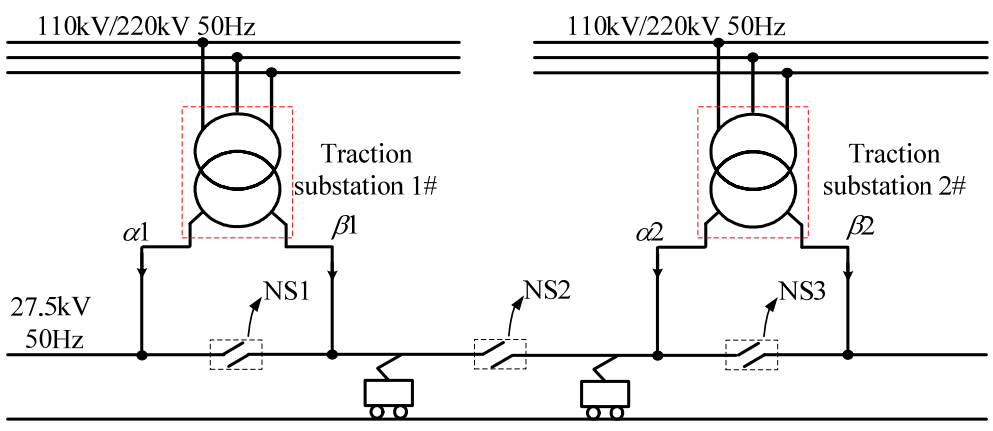

(a)

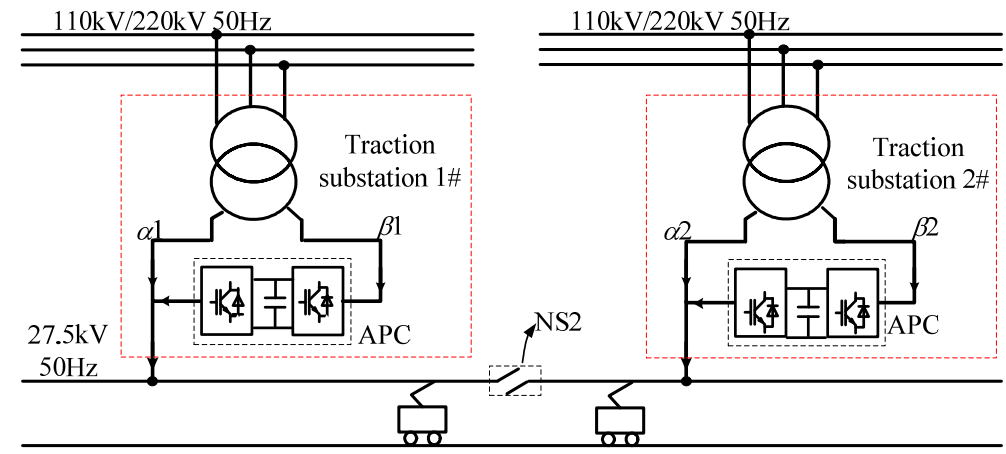

(b)

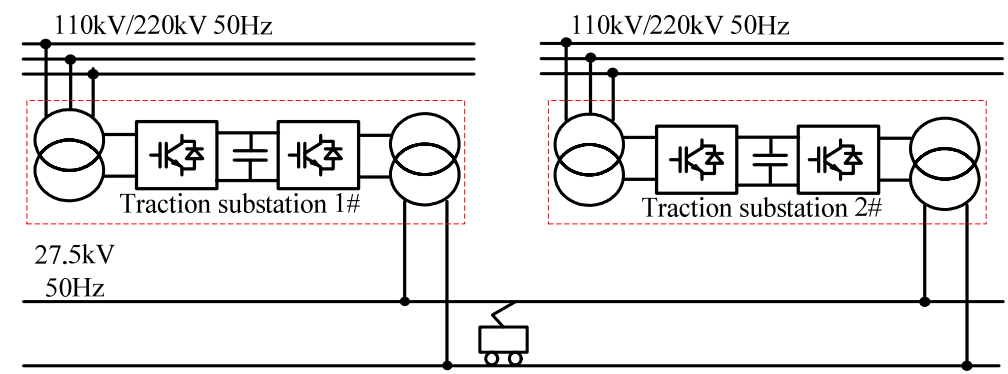

(c)

Figure 1. Traction power supply system modes: (a) The existing traction power supply system;

(b) The co-phase traction power supply system; (c) The advanced traction power supply system.

According to the analysis above, a new traction substation based on a three-phase to single-phase cascade converter in ATPSS is proposed in this paper. The system inherits the advantages of the original traction substation in ATPSS. In this way, problems caused by the output transformer are solved and the interface voltage of the converter is improved to meet the requirements of traction substation capacity.

The paper is organized as follows: Section 2 is dedicated to introducing the proposed three-level neutral point clamped (3L-NPC) cascade converter in a traction substation, and the 3L-NPC three-phase to single-phase is analyzed in detail. The simulation and experimental results are discussed in Section 3. The conclusions are presented in the last part. 


\section{Configuration}

The proposed 3L-NPC cascade converter based on a three-phase to single-phase in a traction substation is shown in Figure 2. The substation consists of a multi-windings step-down transformer connecting to the three-phase grid and several three-phase to single-phase AC-DC-AC converters, which are cascaded in the output terminal. The output of the system is an AC voltage satisfying the load requirements. The traction networks of the adjacent substations connect with each other to form the ATPSS. Meanwhile, the transformers provide isolated input voltages between different converters. Then the outputs of different converters can be connected in series and combined to generated one high voltage traction supply.

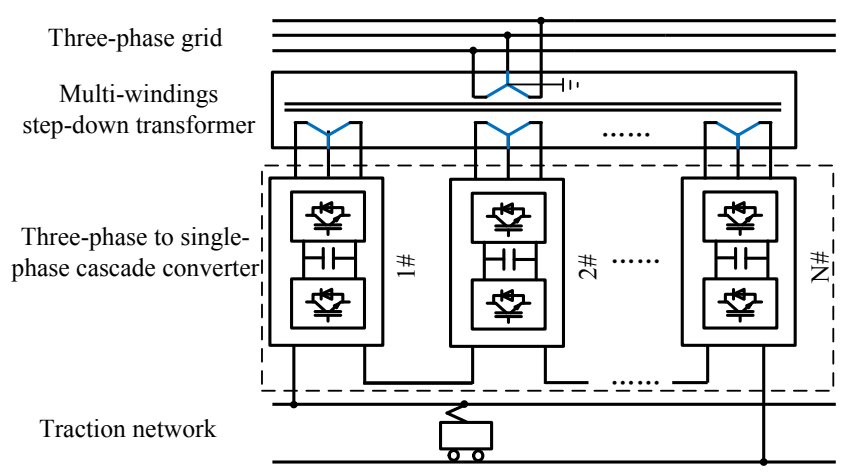

Figure 2. The diagram of proposed traction substation system in advanced traction power supply system (ATPSS).

Owing to the limitations of the present level of power electronic devices, the cascade modules could output several times the voltage of a single module. The 3L-NPC three-phase to single phase converter configuration is shown in Figure 3, taking the traction network capacity and the complexity of control strategy into consideration. The converter is made up of a three-phase 3L-NPC rectifier, auxiliary DC equalizing circuit, LC filter circuit, and single-phase 3L-NPC inverter. The three-phase and single-phase PWM converter can operate in four-quadrant mode, which is able to transfer energy on both sides of a three-phase to single-phase system. It's realized that the system achieves active balanced current of the power grid using the three-phase PWM rectifier system. At the same time, the system provides network capacity in the same phase using a single-phase PWM inverter.

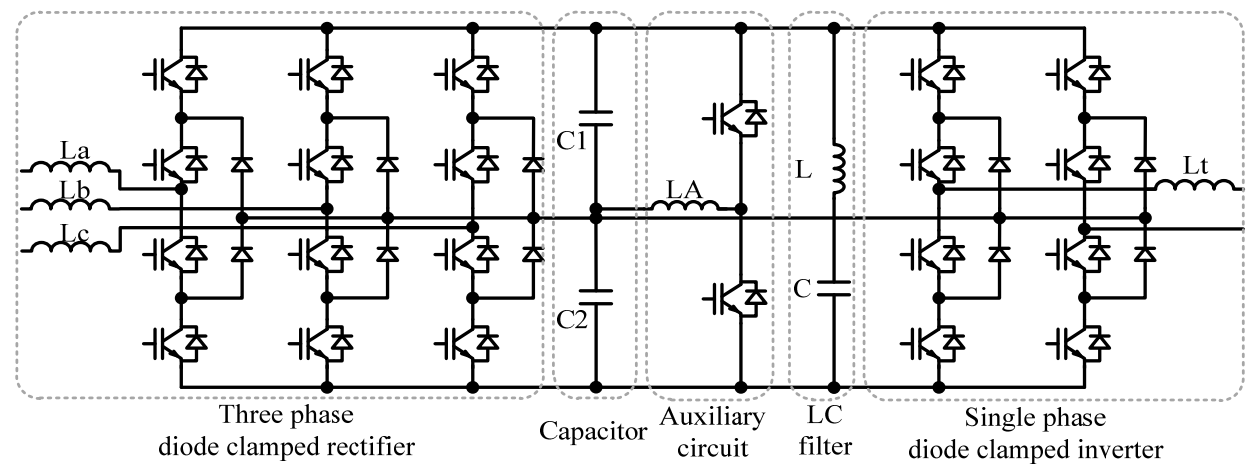

Figure 3. Three-level neutral point clamped (3L-NPC) three-phase to single phase converter with equalizing circuit. 


\subsection{Control of Three-Phase Rectifier}

The three-phase PWM rectifier operates under rectifier mode and active inversion mode in the four-quadrant with the traditional PWM rectifier control strategy [16]. The system controls the active and reactive components of the input signals in the dq coordinate. Both the active current exchange between AC side and DC side and the stabilization control of DC voltage can be achieved. Specifically, a stable DC voltage is achieved by controlling the magnitude and direction of the active current between three-phase grid and the DC capacitor. The detail control principle is shown in Figure 4.

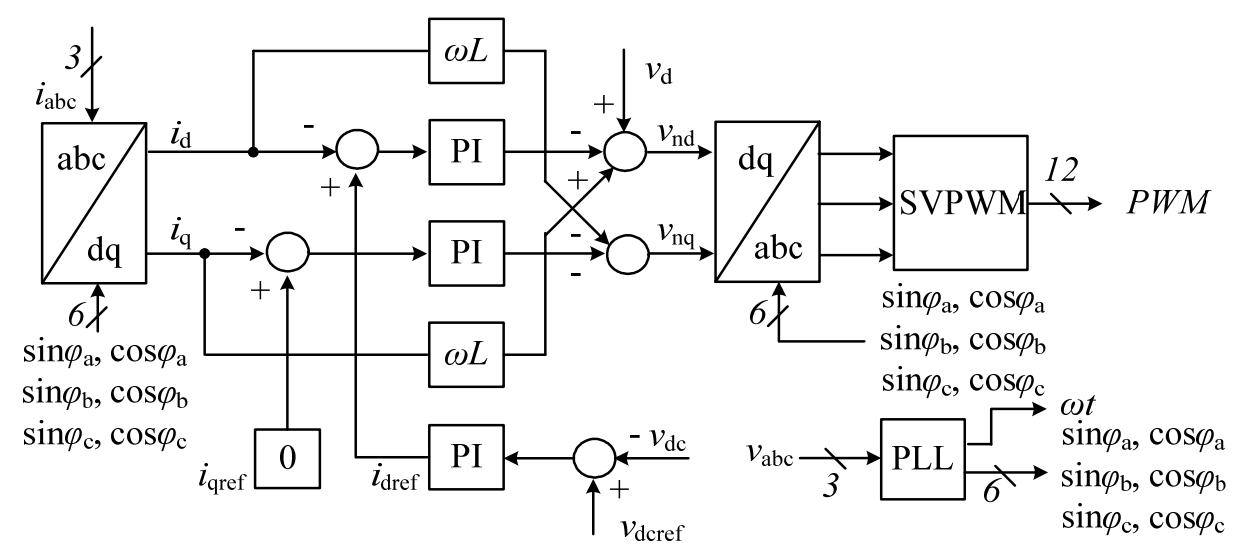

Figure 4. Block control diagram of the three-phase PWM rectifier.

The grid current signal $i_{\mathrm{abc}}$ is transformed into $i_{\mathrm{d}}$ and $i_{\mathrm{q}}$ by the abc-dq transformation and the phase information of voltage $v_{\text {abc}}$, which is acquired with a phase locked loop (PLL). Therefore, active and reactive power decoupling can be achieved. Then the DC voltage $v_{\mathrm{dc}}$ is compared with a given reference voltage $v_{\text {dcref. }}$ The error of $v_{\text {dc }}$ and $v_{\text {dcref }}$ will go through PI (proportional integral) controller and then compared with the d component of the three-phase current, then the result will go through another PI controller as an output current. In the meanwhile, the q component of the three-phase current is compared to a given value 0 , and the PI controller output a value, which controls the q component of the command signal. Then the dq components of the voltage are obtained using the mathematical relationship between the current and voltage after the inverse transformation. Afterwards, the switch control signals will be accomplished with a space vector PWM (SVPWM) control module. By the operation above, the stability of the DC voltage can be achieved. Furthermore, it's able to ensure that rectifier is operating under the unity power factor and the impact on power quality of the public traction network will be reduced.

\subsection{Control of Single-Phase Cascade Inverter}

Assuming that the traction network is working properly, ATPSS requires the cascade converter could actively connect to the traction network and maintain the stability of the port voltage amplitude and frequency in the traction network. Besides, the converter can provide active and reactive current depending on the load requirements and satisfy the need that multiple substations can be automatically assigned current according to the load and the impedance of the traction network. Therefore, the single-phase PWM inverter output voltage can be equivalent to a voltage source, whose frequency, phase and amplitude are adjustable. 
The number of inverter cells $N$ depends on the desired output voltage level, which is synthesized by adding up all the H-bridge cells output voltage as $v_{0}=v_{01}+v_{02}+v_{03}+\ldots+v_{0 N}$. In a cascade system that utilizes equal sets of DC sources $\left(V_{\mathrm{dc} 1}=V_{\mathrm{dc} 2}=V_{\mathrm{dc} 3}=\ldots=V_{\mathrm{dc} N}\right)$, the number of output voltage levels is $N \times(m-1)+1$, where $N$ is the number of cascade cells and $m$ is the number of output voltage levels in each multilevel H-bridge cells, here $m=5$.

It is necessary to get a controllable amplitude, frequency and phase voltage source model in the ATPSS. In this paper, the outer voltage could make a stable modulation. The control principle is shown in Figure 5. $v_{\text {tr, }}$ that is referred as traction network detected actual voltage, is compared with $v_{\text {trref }}$ recognized as a given reference voltage. The result passes the PI controller and its output operates as a co-modulated wave $\left(u_{\mathrm{m}}\right)$ of each $3 \mathrm{~L}-\mathrm{NPC}$ three-phase to single-phase converter module. Carrier $\left(u_{\mathrm{c} N}\right)$ is calculated by phase carrier shift SPWM (PSC-SPWM) technique. Inverter modulation method used in the 3L-NPC three-phase to single-phase converter module is phase disposition SPWM (PD-SPWM) [17].

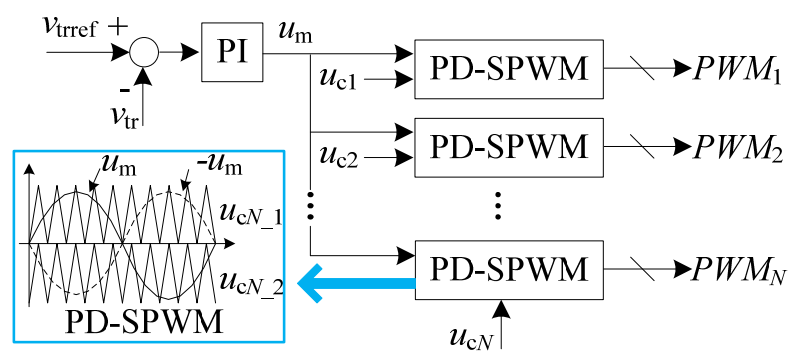

Figure 5. Block control diagram of the single-phase PWM (pulse width modulation) cascade inverter.

The schematic of PSC-SPWM used in cascade inverters is shown in Figure 6. The Fourier fundamental of the output voltage of an H-bridge is:

$$
\frac{v_{\mathrm{o}}}{v_{\mathrm{dc}}}=N m \sin \omega t+\sum_{n=1}^{\infty} \frac{4}{n \pi} \cos \left(\frac{n \pi}{2}\right) \sum_{k=1}^{\infty} J_{k} \frac{m n \pi}{2} \cdot\left[A \sin \left(k \pm n k_{\mathrm{c}}\right) \omega t+2 B \sin (k \omega t) \sin \left(n \omega_{\mathrm{c}} t\right)\right]
$$

In Equation (1), $J_{k}$ is on behalf of the $k$-th Bessel function and $v_{\mathrm{dc}}$ is the DC voltage. Besides, $v_{0}$ represents the output voltage of the inverter.

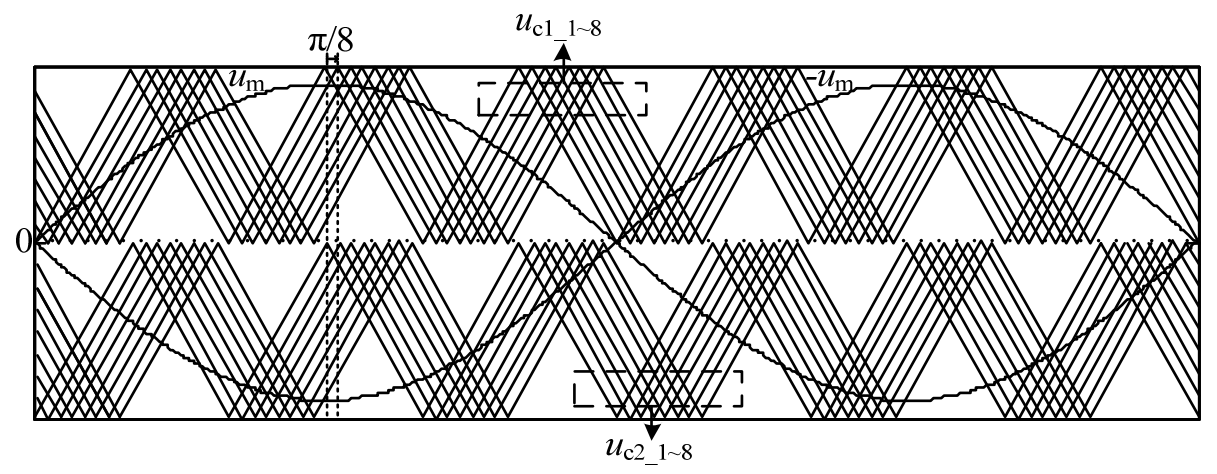

Figure 6. Phase shift carrier schematic.

$$
\left\{\begin{array}{c}
A=\cos n \theta_{1}+\cos n \theta_{2}+\ldots+\cos n \theta_{N} \\
B=\sin n \theta_{1}+\sin n \theta_{2}+\ldots+\sin n \theta_{N}
\end{array}\right.
$$


In Equation (2), $\theta_{\mathrm{k}}(k=1,2,3 \ldots N)$ is phase shift angle. The increasing angle of each H-bridge is $\theta_{\mathrm{k}}=\pi / N(N$ is the number of H-bridge $)$ :

$$
\left\{\begin{array}{l}
A=\cos \left(n \cdot 0 \cdot \frac{\pi}{N}\right)+\cos \left(n \cdot 1 \cdot \frac{\pi}{N}\right)+\ldots+\cos \left[n(N-1) \frac{\pi}{N}\right] \\
B=\sin \left(n \cdot 0 \cdot \frac{\pi}{N}\right)+\sin \left(n \cdot 1 \cdot \frac{\pi}{N}\right)+\ldots+\sin \left[n(N-1) \frac{\pi}{N}\right]
\end{array}\right.
$$

In Equation (3), there is $n=2,4,6 \ldots, B=0$ and when $n<2 N$, the $A=0$ is established. As can be seen from the above derivation, the total output voltage of the H-bridge is the algebraic sum of the basic units. Cascade inverters can be equivalent to a high single carrier frequency converter. The equivalent frequency is $2 N$ times as the frequency of the carrier. In conclusion, PSC-SPWM can be implemented equivalent to the function of higher switching frequency with low power switching devices so that the switching loss can be reduced.

\subsection{DC-Link for the Three-Phase to Single-Phase Converter}

When the multilevel diode clamped converter transfers active power, the DC capacitor voltage will become unbalanced. To solve the problem of DC capacitor voltage unbalance, an inductive auxiliary circuit is added to this paper on the DC-link [18].

The diagram of the inductance equalizing circuit is shown in Figure 7. The specific control principle is as follows: when $V_{\mathrm{c} 1}$ is larger than $V_{\mathrm{c} 2}$, SA1 turns on while $\mathrm{SA} 2$ is off, then the capacitor $\mathrm{C} 1$ will be discharged with the inductance LA. The capacitor's voltage $V_{\mathrm{c} 1}$ decreases, and the inductance's current increases. Since the energy stored in $\mathrm{C} 1$ is delivered to LA via the path shown in Figure 7a, the voltage $V_{\mathrm{c} 1}$ decreases and $V_{\mathrm{c} 2}$ remains unchanged. Meanwhile, the discharge current $i$ LA1 will increase linearly from zero. Secondly, SA1 is turned off, and SA2 also maintains an off state. The anti-parallel diode DA2 provides a discharge path for LA as shown in Figure $7 b$. The energy stored in LA will be delivered to C2. Therefore $V_{\mathrm{c} 2}$ increases, whereas $V_{\mathrm{c} 1}$ remains unchanged. This stage will be ended once $i_{\mathrm{LA} 1}$ reaches zero. The process will not end up until $V_{\mathrm{c} 1}=V_{\mathrm{c} 2}$. On the contrary, if $V_{\mathrm{c} 1}<V_{\mathrm{c} 2}$, the process is just the opposite.

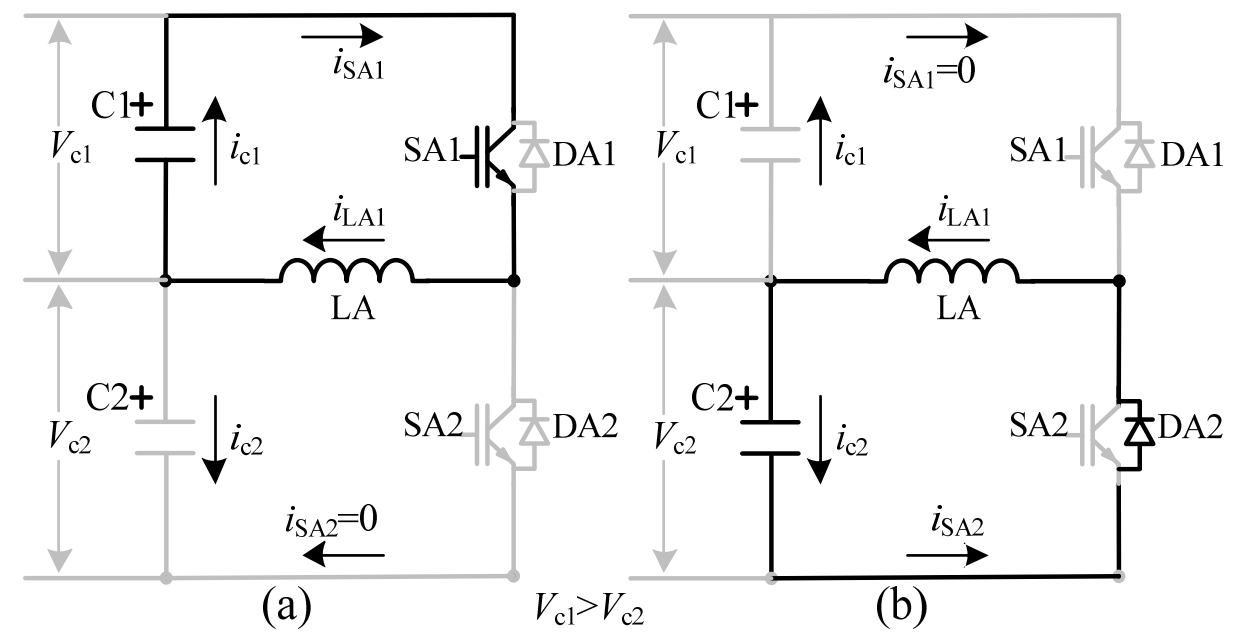

Figure 7. The inductance equalizing circuit of 3L-NPC. (a) Discharge current path from $\mathrm{C} 1$ to LA at $V_{\mathrm{C} 1}>V_{\mathrm{C} 2}$ stage 1 ; (b) Charge current path from LA to $\mathrm{C} 2$ at $V_{\mathrm{C} 1}>V_{\mathrm{C} 2}$ stage 2. 
As is well known, a double line-frequency ripple of DC voltage would appear on the DC-link [19]. In this paper, a LC filter circuit is designed to eliminate the double line-frequency ripple:

$$
i_{\mathrm{dc} 2}=-\frac{V_{\mathrm{t}} I_{\mathrm{t}}}{N V_{\mathrm{dc}}} \cos \left(2 \omega_{0} t-\varphi\right)
$$

where, $i_{\mathrm{dc} 2}$ is the twice grid-frequency current, $V_{\mathrm{t}}$ and $I_{\mathrm{t}}$ are the voltage and current of cascade inverter output, respectively. $V_{\mathrm{dc}}$ is the DC-link voltage of each three-phase to single-phase converter, $\omega_{0}$ is angular frequency, $\varphi$ is the power factor angle of the load. When the circuit is under resonant state, $i_{\mathrm{dc} 2}$ flow through the LC filter circuit. Therefore, the capacitor's voltage $v_{\mathrm{c}}$ of the LC filter is shown in Equation (5):

$$
v_{\mathrm{C}}=-\frac{V_{\mathrm{t}} I_{\mathrm{t}}}{2 C \omega_{0} N V_{\mathrm{dc}}} \sin \left(2 \omega_{0} t-\varphi\right)
$$

Generally, the amplitude of $v_{\mathrm{c}}$ is less than $10 \%$ of DC-link voltage. So the L (inductor) and C (capacitor) is designed in Equations (6) and (7):

$$
\begin{gathered}
C \geq \frac{5 V_{\mathrm{t}} I_{\mathrm{t}}}{\omega_{0} N V_{\mathrm{dc}}^{2}} \\
L=\frac{1}{4 C \omega_{0}{ }^{2}}
\end{gathered}
$$

\section{Simulation and Experiment Results}

\subsection{Simulation and Analysis}

In order to verify the system's control strategy proposed above, a 3L-NPC three-phase to single-phase cascade converter for a substation shown in Figure 2 is used to conduct a simulation by MATLAB/SIMULINK (MathWorks, Natick, MA, USA) in this paper. The main simulation parameters are listed in Table 1.

Table 1. System and control parameters.

\begin{tabular}{cc}
\hline Parameters & Values \\
\hline Three-phase power source voltage & $110 \mathrm{kV}$ \\
Rated frequency & $50 \mathrm{~Hz}$ \\
The standard of multi-windings transformer & $110 \mathrm{kV} / 3.5 \mathrm{kV}$ \\
The standard of IGBT & $6.5 \mathrm{kV}$ \\
Cells & 8 \\
DC-link voltage & $7 \mathrm{kV}$ \\
DC-link capacitance & $3 \mathrm{mF}$ \\
The inductance of three-phase input side & $3 \mathrm{mH}$ \\
The inductance of single-phase output side & $2 \mathrm{mH}$ \\
The reference voltage of traction network & $27.5 \mathrm{kV}$ \\
The inductance of auxiliary circuit & $1 \mathrm{mH}$ \\
The filter circuit & $3 \mathrm{mF} / 0.84 \mathrm{mH}$ \\
Load & $100 \Omega$ \\
Switching frequency of carrier & $6 \mathrm{kHz}$ \\
\hline
\end{tabular}


A discrete modeling algorithm is used in the simulation. The sampling time is $1 \mu$ s. The influence of double line-frequency ripple in three-phase to single-phase on the DC-link is exhibited in this paper. What's more, the performance characteristics of no-load and load-supporting is also presented by this simulation. The simulation time is $1.2 \mathrm{~s}$ and there is no-load before $0.4 \mathrm{~s}$, while the system is loaded after $0.4 \mathrm{~s}$. During this period time, the LC filter circuit comes into operation after $0.9 \mathrm{~s}$.

The DC voltage $v_{\text {dc }}$ is shown in Figure 8 . As can be seen from the figure, the voltage of each capacitor become stable at $3.5 \mathrm{kV}$ after about $0.1 \mathrm{~s}$ regulation time at no-load. When the circuit is loaded at $0.4 \mathrm{~s}$, the system responds quickly with restoring homeostasis in $0.2 \mathrm{~s}$. Because of the double line-frequency ripple added into the single-phase inverter DC side, the voltage produces slight fluctuations at $3.5 \mathrm{kV}$ in the steady state, and the amount of pulsation is about $5.7 \%$ of the DC voltage. After $0.9 \mathrm{~s}$, the double line-frequency ripple disappears as the LC filter circuit going up. Besides, the results verified that the voltage equalization could be achieved by the inductance equalizing circuit.

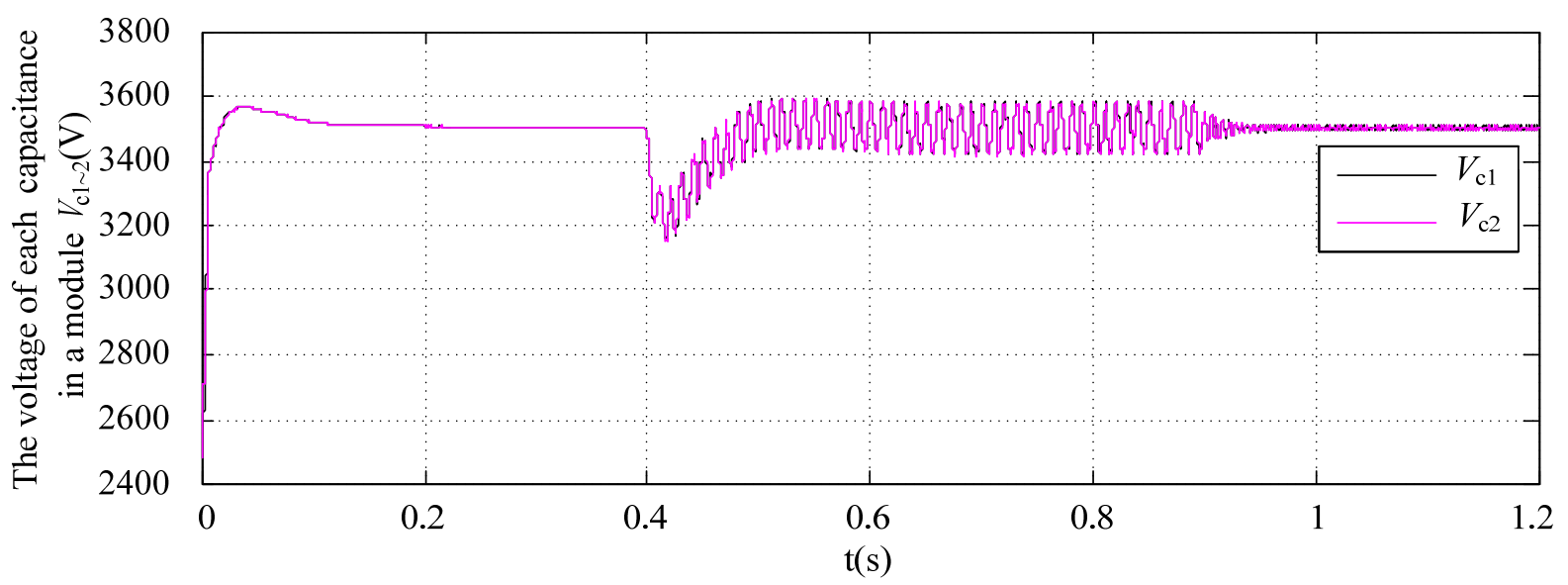

Figure 8. The DC voltage of three-phase to single-phase converter.

The currents $i_{\text {sabc }}$ of the three-phase to single-phase converter in the grid are displayed in Figure 9. The currents change a lot during the simulation process. Before $0.2 \mathrm{~s}$, the three-phase power charges the DC capacitances. Because the system is at no-load in $0-0.4 \mathrm{~s}$, the output currents are substantially zero before the DC voltage charging is completed. When the load is added at $0.4 \mathrm{~s}$, the currents increase quickly. The waveforms become irregular with a large number of injected harmonics, owing to the double line-frequency ripple appearing on the DC-link of the three-phase to single-phase converter. The LC filter circuit is put into operation after $0.9 \mathrm{~s}$ and the double line-frequency ripple is eliminated rapidly. During 1.16-1.20 s, the currents exhibit a good sinusoidal waveform and the current distortion disappears from the LC filter circuit. What's more, the Total Harmonic Distortion (THD) of the three-phase currents $i_{\text {sabc }}$ is $2.46 \%$ in the steady situation. Figure 10 shows that the voltage is in phase with the current of phase A. The results verify that the converter designed in this paper can run at unity power factor. In addition, a good dynamic response was found during system startup. The three-phase to single-phase converter is equivalent as well as a resistive load for three-phase grid.

The output voltage of the cascade converters, namely traction network voltage waveform $v_{\text {tr }}$, is illustrated in Figure 11. The voltage waveform is a multi-level staircase under no-load. The output voltage nearly becomes a sinusoidal waveform after $0.4 \mathrm{~s}$ since the inductance filter circuits are used in inverters. 


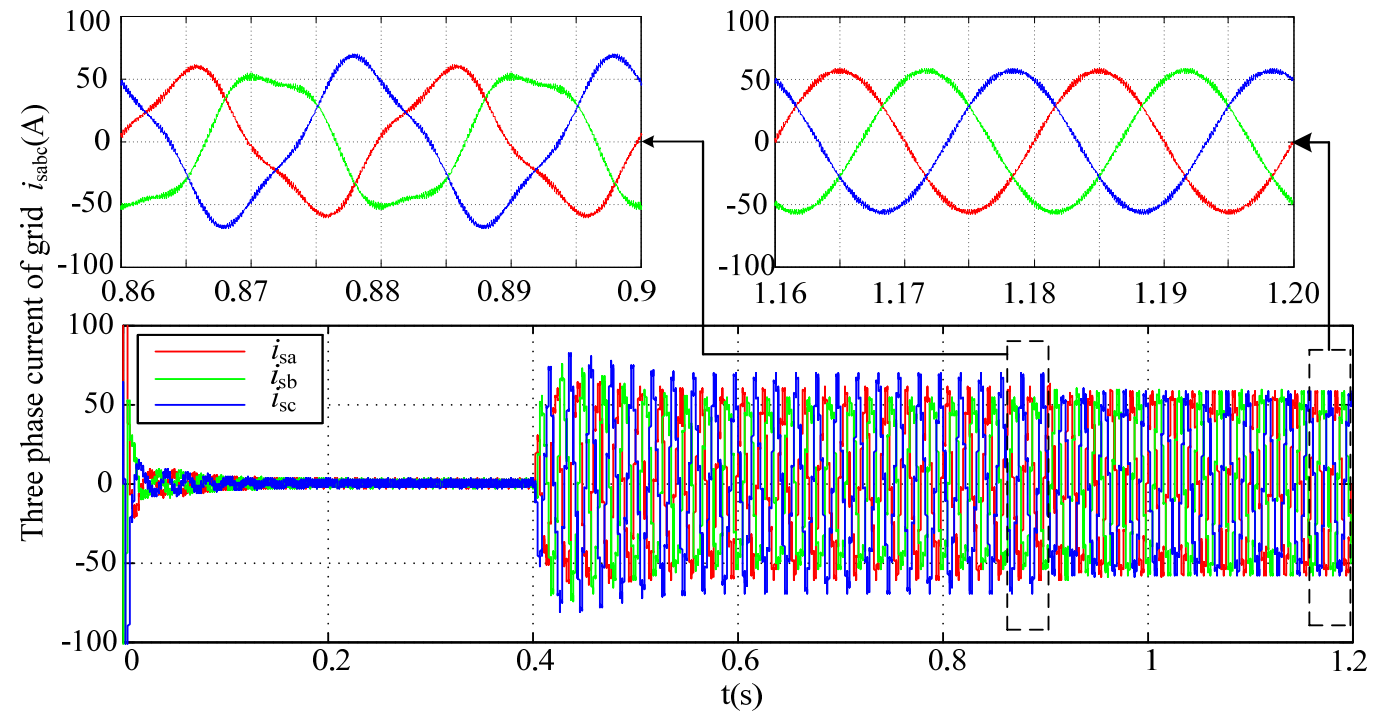

Figure 9. The currents in the grid.

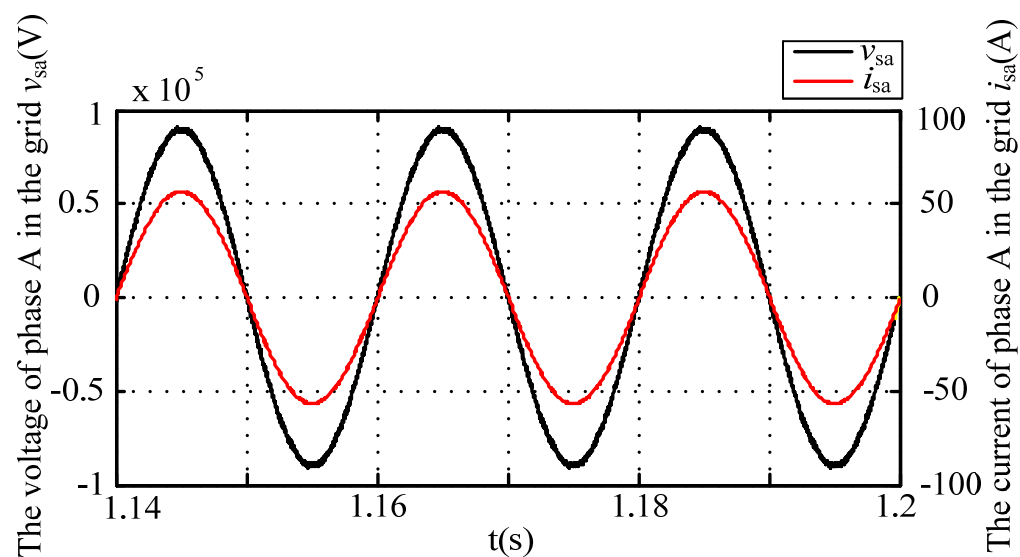

Figure 10. The voltage and current of phase A in the grid.

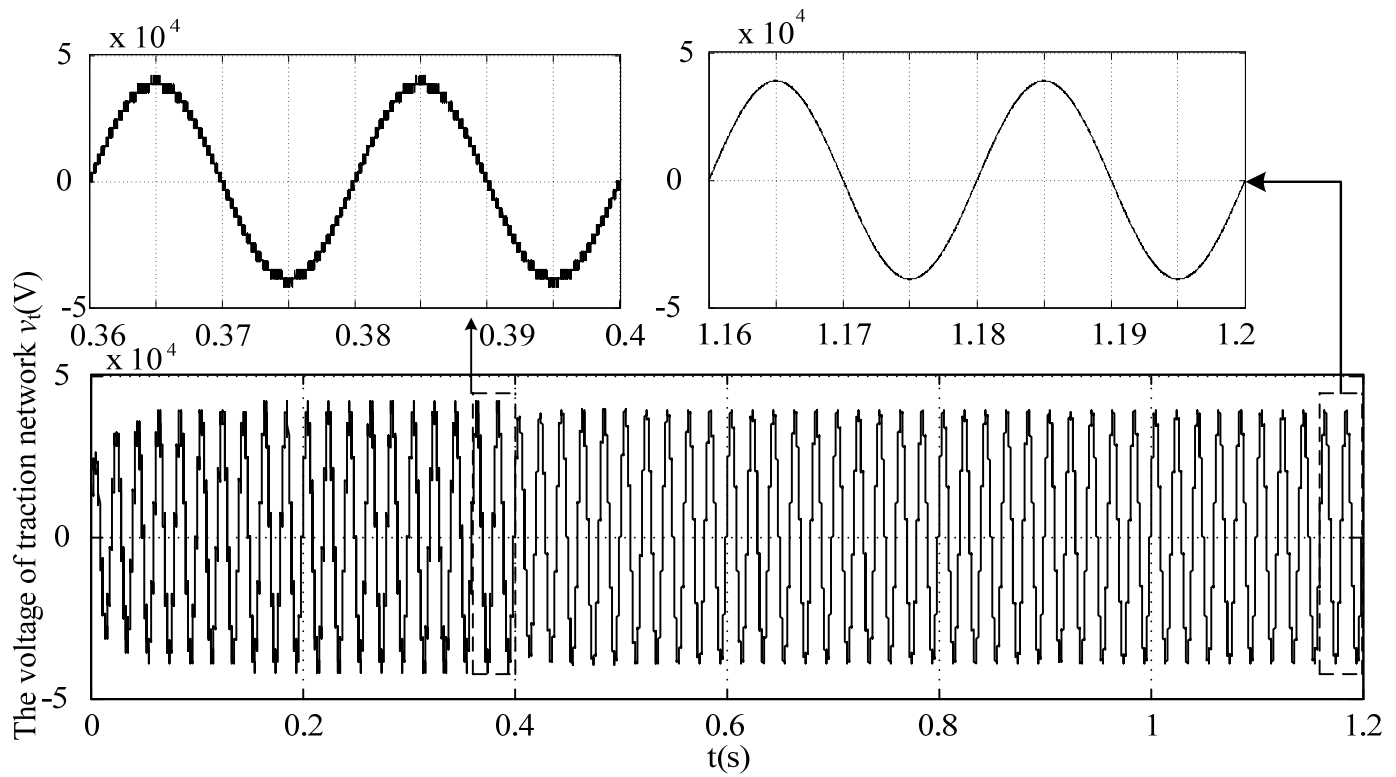

Figure 11. The voltage of traction network. 
With the rising output cascade levels, the switching frequency decreases. Therefore, the loss of switching also comes down. As is shown in Figure 12, the THD of the voltage of traction network is $0.31 \%$, which illustrates that the cascade system could reduce the harmonics and promote power quality. Meanwhile, the cascade system has low requirements for filter circuit design, when the cascade number is high enough, the harmonic content is very low. Then it is possible to cancel the filter circuit to save on circuit costs.

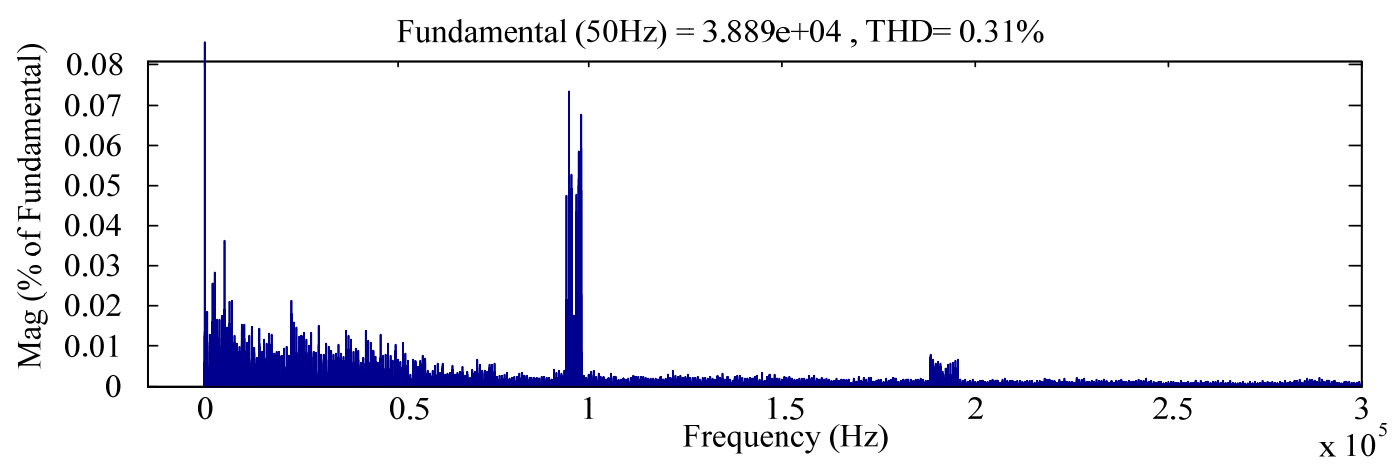

Figure 12. The Total Harmonic Distortion (THD) of voltage of the traction network.

\subsection{Experiments and Analysis}

In order to verify the performance of the cascade system proposed, an experimental setup of a 3L-NPC three-phase to single-phase cascade converter has been developed. Figure 13 is a photo of the prototype. The major experimental parameters is listed in Table 2. All the control algorithms and assistant modules are implemented by Verilog-HDL (Hardware Description Language), one of universal IEEE industry standard hardware description languages used to describe digital systems and design hardware realization in code method.

In Figure $14 \mathrm{a}$, the phase A voltage $v_{\mathrm{sa}}$ and current $i_{\mathrm{sa}}$ of transformer on the primary side are illustrated, and both the voltage and current are in the same phase, so the rectifier is working within unity-power factor limits. For the three-phase grid, the cascade system is a pure resistive load. The current $i_{\text {sa }}$ on the primary side is added up by the A phase current $i_{\mathrm{a} 1}$ and $i_{\mathrm{a} 2}$ in the secondary side, which is displayed with $\mathrm{Ch} 2$ and Ch4. Figure 14b presents the DC voltage, the voltage and current of load without the LC filter circuit, while Figure $14 \mathrm{c}$ shows the same variables within the LC filter circuit. An obvious double line-frequency ripple of DC voltage appears without LC filter circuit, while it disappears within LC filter circuit, which proves the analysis above. The ripple has a bad influence on the inverter output, producing a slight shift on the output voltage. When the LC filter circuit begins to work, the shift disappears. It is confirmed that LC filter circuit is effective for the ripple. Figure $14 \mathrm{~d}$ shows the voltage of output and

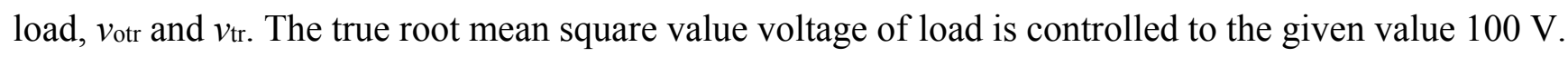
The waveform is very smooth and verifies the control strategy of the converter. A high quality voltage could be obtained from the proposed converter. Figure 14e exhibits the voltage and current of load when the load step changes. In two fundamental cycles, the voltage and current make a quick adjustment to recover sinusoidal waveforms. It follows that the dynamic characteristics of control system is verified. Figure $14 \mathrm{f}$ also demonstrates a satisfactory control performance. The steady-state characteristics and dynamic characteristics of the system are greatly increased. 


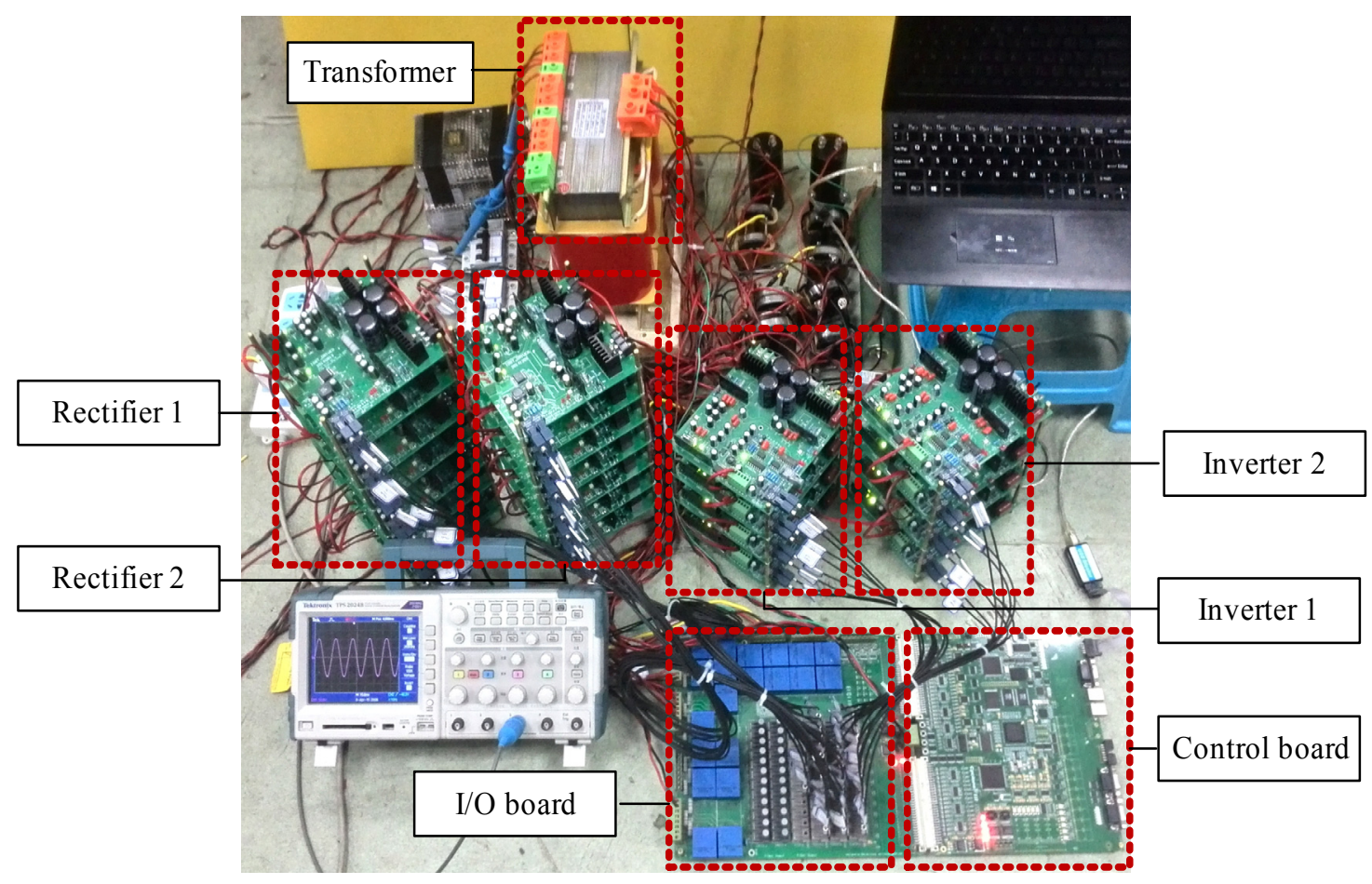

Figure 13. Photo of the experimental prototype.

Table 2. Experimental circuit parameters.

\begin{tabular}{cc}
\hline Parameters & Values \\
\hline The voltage on primary and secondary side of transformer & $50 \mathrm{~V} / 50 \mathrm{~V}$ \\
Cells & 2 \\
Rated frequency & $50 \mathrm{~Hz}$ \\
DC-link voltage & $100 \mathrm{~V}$ \\
DC-link capacitance & $470 \mu \mathrm{F}$ \\
The inductance of three-phase input side & $2 \mathrm{mH}$ \\
The inductance of single-phase output side & $2 \mathrm{mH}$ \\
The inductance of auxiliary circuit & $1 \mathrm{mH}$ \\
The filter circuit & $2.2 \mathrm{mF} / 1 \mathrm{mH}$ \\
Load & $100 \Omega$ \\
Switching frequency of carrier & $3 \mathrm{kHz}$ \\
\hline
\end{tabular}

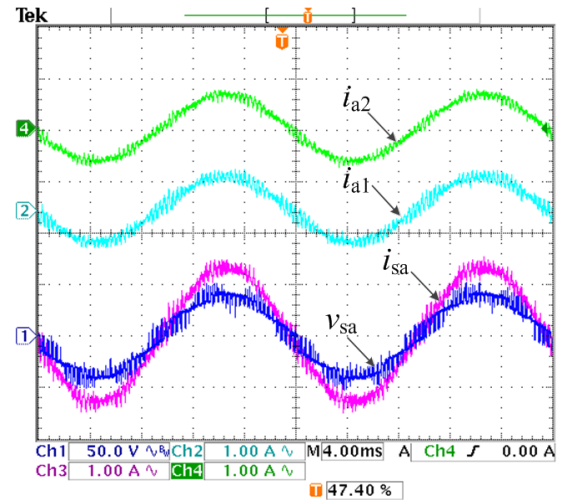

(a)

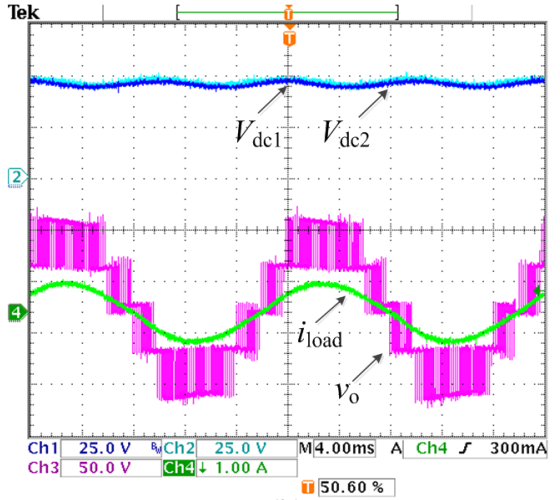

(b)

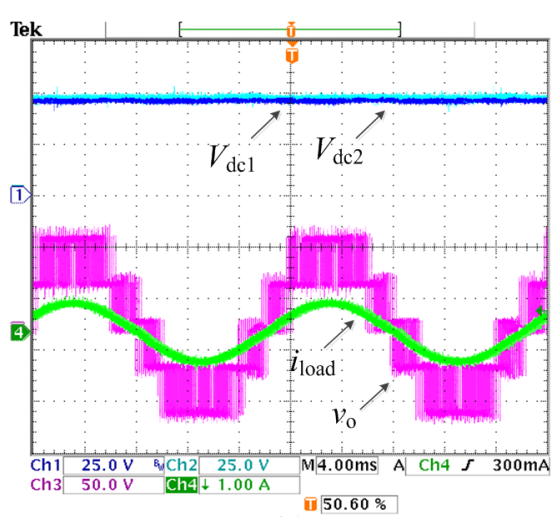

(c)

Figure 14. Cont. 


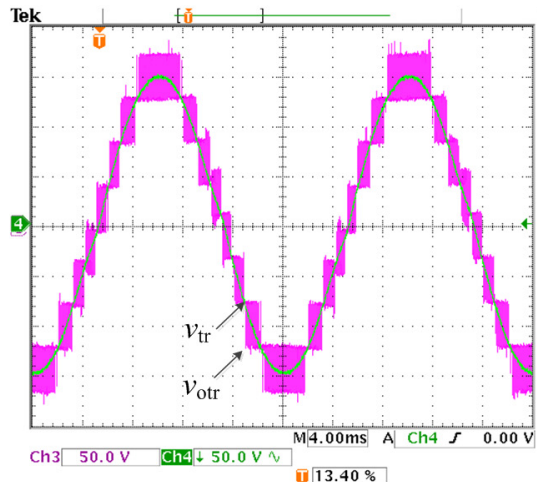

(d)

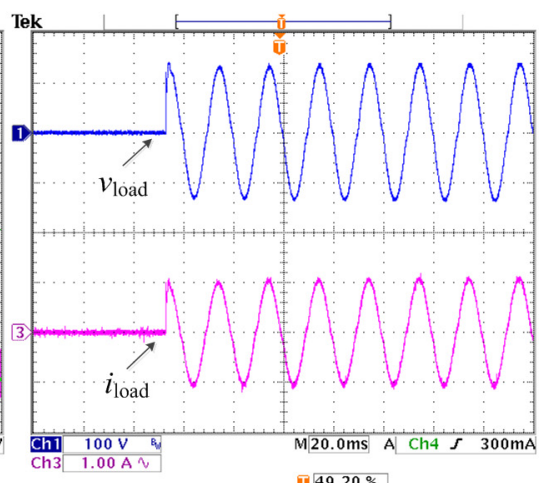

(e)

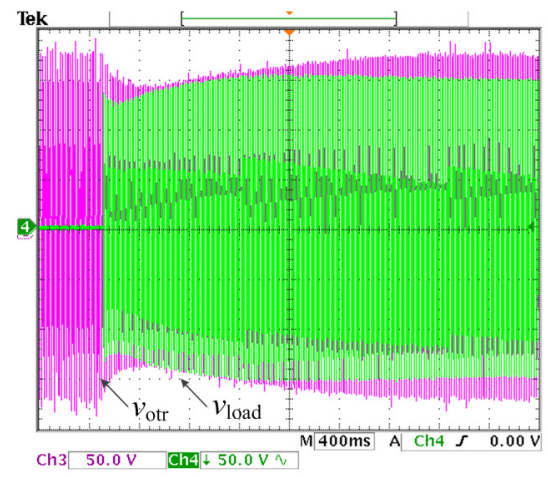

(f)

Figure 14. Experiment results: (a) The currents of transformer, $\mathrm{CH} 1$ : the voltage of phase A in the primary side $v_{\text {sa }}, \mathrm{CH} 3$ : the current of phase A on the primary side $i_{\text {sa, }} \mathrm{CH} 2$ : the current of phase A on secondary side $i_{\mathrm{a} 1}, \mathrm{CH} 4$ : the current of phase A on secondary side $i_{\mathrm{a} 2}$; (b) The DC voltage without LC filter circuit and voltage and current of load, CH1: DC voltage $V_{\mathrm{dc} 1}, \mathrm{CH} 2$ : DC voltage $V_{\mathrm{dc} 2}, \mathrm{CH} 3$ : output voltage $v_{\mathrm{o}}, \mathrm{CH} 4$ : the current of load $i_{\text {load}}$; (c) The DC voltage with LC filter circuit and voltage and current of load, $\mathrm{CH} 1$ : DC voltage $V_{\mathrm{dc} 1}, \mathrm{CH} 2$ : DC voltage $V_{\mathrm{dc} 2}, \mathrm{CH} 3$ : output voltage $v_{\mathrm{o}}, \mathrm{CH} 4$ : the current of load $i_{\text {load}}$; (d) The output voltage and load voltage, $\mathrm{CH} 3$ : output voltage $v_{\text {otr, }} \mathrm{CH} 4$ : load voltage $v_{\text {tr }}$; (e) The voltage and current of load when the load step change, CH1: load voltage vload, CH3: load current $i_{\text {load}}$; (f) Dynamic waveforms of voltage when the load step changes, CH3: output voltage $v_{\text {otr, }} \mathrm{CH} 4$ : load voltage $v_{\text {tr. }}$

\section{Conclusions}

A 3L-NPC three-phase to single-phase cascade converter for railway substations is proposed in this paper. The related control strategy of rectifier and cascade inverter are analyzed in detail, respectively. In addition, an inductance equalizing circuit and LC filter on the DC-link are designed. Based on the analysis above, a simulation system is built. The results show that the converter could satisfy the requirements of voltage and capacity for a traction network. The goal of unity power factor with low harmonic content is also met in the three-phase grid. Besides, a good dynamic and static performance is also exhibited in this paper. Moreover, the double line-frequency ripple of converter could be cleared up by the LC filter circuit, reducing the negative impact on the power quality of the traction network. The small-scale experimental results demonstrate the basic function and dynamic performance of the proposed system as well.

\section{Acknowledgments}

This work was supported by the National Natural Science Foundation of China (Grant Nos. 51477144, 51377004).

\section{Author Contributions}

The layout of the experiment prototype was done by Zeliang Shu. Zhanghai Shi offer a lot of suggestions and help for this paper. Yingying Zhou performed the simulations for the system. 
$\mathrm{Xu}$ Peng contributed to the experiments. Aiping Guo performed the experiments and wrote the paper.

Xiaoqiong He contributed to all of the parts.

\section{Conflicts of Interest}

The authors declare no conflict of interest.

\section{References}

1. Wang, W.; Liu, Y. Geopolitics of global climate change and energy security. Chin. J. Popul. Resourc. Environ. 2015, 13, 1-8.

2. Hu, H.T.; He, Z.Y.; Gao, S.B. Passive filter design for China high-speed railway with considering harmonic resonance and characteristic harmonics. IEEE Trans. Power Deliv. 2015, 1, 505-514.

3. Shu, Z.; Xie, S.; Li, Q. Single-phase back-to-back converter for active power balancing, reactive power compensation, and harmonic filtering in traction power system. IEEE Trans. Power Electron. 2011, 26, 334-343.

4. Han, Z.; Liu, S.; Gao, S. An Automatic System For China High-Speed Multiple Unit Train Running Through Neutral Section With Electric Load. In Proceedings of the 2010 Asia-Pacific Power and Energy Engineering Conference (APPEEC), Chengdu, China, 28-31 March 2010.

5. Shu, Z.; Xie, S.; Lu, K.; Zhao, Y.; Nan, X.; Qiu, D.; Zhou, F.; Gao, S.; Li, Q. Digital detection, control, and distribution system for co-phase traction power supply application. IEEE Trans. Ind. Electron. 2013, 60, 1831-1839.

6. Abrahamsson, L.; Schütte, T.; Östlund, S. Use of converters for feeding of AC railways for all frequencies. Energy Sustain. Dev. 2012, 3, 368-378.

7. He, X.; Shu, Z.; Peng, X.; Zhou, Q.; Zhou, Y.; Zhou, Q.; Gao, S. Advanced Cophase Traction Power Supply System Based on Three-Phase to Single-Phase Converter. IEEE Trans. Power Electron. 2014, 29, 5323-5333.

8. Shu, Z.; Xie, X.; Jing, Y. Advanced Co-Phase Traction Power Supply Simulation Based on Multilevel Converter. In Proceedings of the 2011 2nd International Congress on Computer Applications and Computational Science; Springer: Berlin, Germany, 2012; pp. 459-465.

9. Odeh, C.I.; Ojo, O. Analytical model of four-cell grid-connected multilevel cascaded H-bridge DC-to-AC converter. Electr. Power Compon. Syst. 2013, 41, 824-842.

10. Nasiri, A.; Amac, A.E.; Emadi, A. Series-parallel active filter/uninterruptible power supply system. Electr. Power Compon. Syst. 2004, 32, 1151-1163.

11. Ma, K.; Munoz-Aguilar, R.S.; Rodriguez, P.; Blaabjerg, F. Thermal and efficiency analysis of five-level multilevel-clamped multilevel converter considering grid codes. IEEE Trans. Ind. Appl. 2014, 50, 415-423.

12. Edpuganti, A.; Rathore, A.K. Fundamental switching frequency optimal pulsewidth modulation of medium-voltage nine-level inverter. IEEE Trans. Ind. Electron. 2015, 62, 4096-4104.

13. Malinowski, M.; Gopakumar, K.; Rodriguez, J.; Perez, M.A. A survey on cascaded multilevel inverters. IEEE Trans. Ind. Electron. 2010, 57, 2197-2206. 
14. Luther-King, N.; Narayanan, E.M.S.; Coulbeck, L.; Crane, A.; Dudley, R. Comparison of trench gate IGBT and CIGBT devices for increasing the power density from high power modules. IEEE Trans. Power Electron. 2010, 25, 583-591.

15. Shenai, K.; Chattopadhyay, A. Optimization of High-Voltage Wide Bandgap Semiconductor Power Diodes. IEEE Trans. Electron. Devices 2015, 62, 359-365.

16. Rim, C.T.; Choi, N.S.; Cho, G.C.; Cho, G.H. A complete dc and ac analysis of three-phase controlled-current pwm rectifier using circuit d-q transformation. IEEE Trans. Power Electron. 1994, 9, 390-396.

17. Ghias, A.M.; Pou, J.; Agelidis, V.G.; Ciobotaru, M. Voltage balancing method for a flying capacitor multilevel converter using phase disposition pwm. IEEE Trans. Ind. Electron. 2014, 12, 6538-6546.

18. Shu, Z.; Zhu, H.; He, X.; Ding, N.; Jing, Y. One inductor based auxiliary circuit for DC-link capacitor voltage equalization of diode-clamped multilevel converter. IET Power Electron. 2013, 6, 1339-1349.

19. Liu, C.; Lai, J.S. Low frequency current ripple reduction technique with active control in a fuel cell system with inverter load, IEEE Trans. Power Electron. 2007, 22, 1429-1436.

(C) 2015 by the authors; licensee MDPI, Basel, Switzerland. This article is an open access article distributed under the terms and conditions of the Creative Commons Attribution license (http://creativecommons.org/licenses/by/4.0/). 